\title{
Further observations from an experience of 660 cases of stereotactic tractotomy
}

\author{
GEOFFREY KNIGHT* \\ F.R.C.S., F.R.C.Psych.
}

\author{
Royal Postgraduate Medical School
}

\begin{abstract}
Summary
A study of the results of some 660 cases of stereotactic tractotomy shows that these have been consistent through a 12-year period, more than $50 \%$ of cases of resistant depression can be set free of medical care and another $25 \%$ at least can be improved. Comparable results are also obtained in obsessional illness and anxiety states, particularly those in which there is a depressive component.

The original localization of the target site described in 1964 has not required modification but pathological studies and anatomical research has revealed new features concerning the anatomical connections affected by this operation.

The lesion beneath the head of the caudate nucleus does not extend quite so far as the substantia innominata and should therefore be called subcaudate tractotomy. Connections from the anterior cingulate region and posterior orbital cortex are severed at this site but amygdalo-hypothalamic fibres are not interrupted directly, however; the projection from the amygdala to the dorsal median nucleus sends a radiation to the posterior orbital cortex which is divided here. In addition, important projections from frontal cortex to hypothalamus which bring the external milieu into association with the limbic system pass downwards through the target area beneath the head of the caudate nucleus and are also divided at this point, the localized lesion, therefore, produces a marked effect upon fibres which are concerned in emotional activity. The wellnigh specific effect in cases of depression raises the question whether the operation acts by modifying the intensity of emotional reactivity through limbic connections or has a more specific effect upon the cause of abnormal reactivity through fronto-hypothalamic connections exerting an influence on monoamine production in the hypothalamus.
\end{abstract}

THE extension of the field of psychosurgery, which has resulted from the development of precise localized procedures and atraumatic methods of operation under stereotactic control, has yielded information concerning the effect of operation at

* Correspondence: Psychosurgical Department, Regional Neurosurgical Centre, Brook Hospital, London S.E.18 many varied sites, as recorded in The proceedings of the Second International Conference on Psychosurgery held in 1970 in Copenhagen (Psychosurgery, 1972). The levels of success obtained by operation at widely separated sites, indicates that we are concerned with the modification of the relationship between the external milieu and limbic system and between limbic system and consciousness, resulting in a modification of emotional behaviour, this effect being achieved by operation at selected sites within a complex circuitry (Knight, 1972a).

The operation of stereotactic tractotomy (Knight, 1964) has been employed in some 660 cases. A study of the results shows that these have been consistent throughout a 12-year period, confirming the original estimation (Knight, 1965) that more than $50 \%$ of cases of resistant depression can be made free of medical care and over $25 \%$ at least can be improved after failure of standard psychiatric treatment over a period of years, and that a similar degree of benefit can also be obtained in obsessional illness and phobic anxiety states (Ström-Olsen \& Carlisle, 1971). The operation has proved a useful next stage in the treatment of psychiatric illness and there has been no reason to alter the original localization of the target site, which was described in 1964 as corresponding to the last $2 \mathrm{~cm}$ of a $6 \mathrm{~cm}$ restricted orbital undercutting incision, lying beneath the head of the caudate nucleus and overlying Area 13 of the orbital cortex. Indeed, we have come to adhere closely to this localization.

In some early cases exhibiting cerebral atrophy, the depth of implantation was restricted for a few millimetres. Post-mortem examination some years later in elderly patients who died of intercurrent illness showed that where such a restriction had been made the lesion might lie too far anteriorally (Corsellis, 1969). In four elderly patients there was an escape of white matter internal to the lesion on one side or both; this may have been due to rotation or to the fact that in a brain of that size and shape a target $1 \mathrm{~cm}$ from the middle line was too far lateral and the seeds should have been directed further mesially. Since 1969, air encephalography has been employed before operation to check the position of mid-line 
structures and the target has been moved mesially in the anterio-posterior view. Instead of centring it $1.4 \mathrm{~cm}$ from the mid-line which, allowing for magnification and radioactivity, produced a lesion extending to $1 \mathrm{~cm}$ of the mid-line, the target is centred at $1 \mathrm{~cm}$, which brings the inner edge of the lesion to $0.6 \mathrm{~cm}$ from the mid-line. A full depth of implantation is used in all cases (Knight, 1972b).

The use of air encephalography not only checks the mid-line and prevents any errors resulting from slight rotation of the head but demonstrates the outline of the anterior horns, which can be distorted or expanded following previous leucotomy operation. In two cases in which the operation had been performed without air encephalography, following a previous leucotomy, the anterior seed of the middle row entered the expanded ventricle without producing any harmful clinical effect (Corsellis \& Jack, 1973). We have previously emphasized the importance of low approach in order to prevent damage to the caudate nucleus. In one case an assistant implanted seeds into the corpus striatum, the patient dying after an interval of marked confusion, restlessness, and hypostatic changes, this being the only operative mortality in a series of 660 cases. The importance of a low approach cannot be over emphasized.

Whilst only minor modifications of technique have proved necessary, new knowledge has modified our views concerning the anatomical circuits affected and possible mechanisms by which good effects are produced. We have also come to believe that the formation of a standard lesion in a large series of

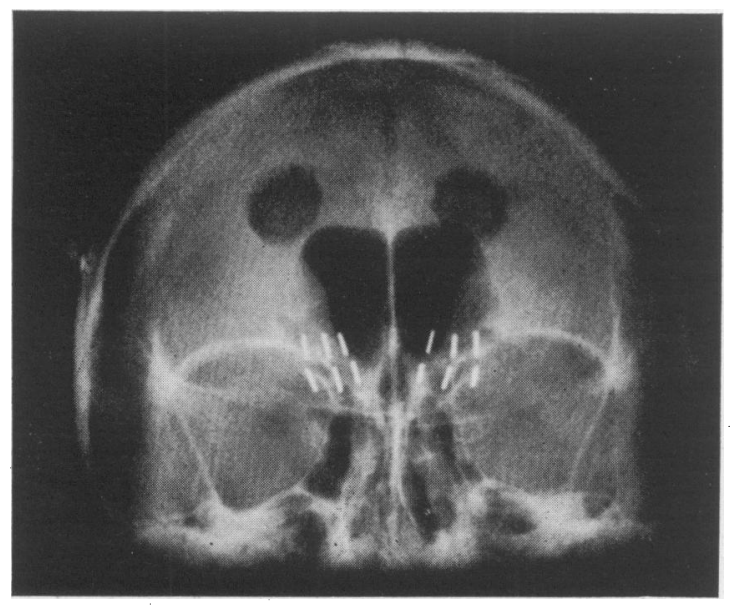

FIG. 1. Anteroposterior X-rays showing the type of operation using air encephalography. Three lines of seeds are implanted and a target point $1 \mathrm{~cm}$ from the mid-line, bringing the area of destruction up to $0.6 \mathrm{~cm}$ from the mid-line. cases reveals certain differences in response in clinical subcategories which exist within the major diagnostic classifications (Knight, 1972b).

\section{Anatomical considerations}

Attention was directed to the target area as a result of observations in some 500 cases of restricted orbital undercutting (Knight \& Tredgold, 1955) which indicated that the maximum effect was produced in the terminal $2 \mathrm{~cm}$ of the incision where it enters beneath the caudate nucleus and overlies Area 13 and part of Area 14. Knight (1960) stated that there appeared to be a concentration of fibres at this point, division of which would produce an adequate relief of symptoms without disturbing fibres elsewhere in the brain. One wondered whether this might prove to be a target for a stereotactic procedure, although at that time it was impossible to identify fully the fibre tracts involved. It seemed impossible that the isolation of so small an area of agranular cortex alone should be responsible for the beneficial effects which the undercutting operation produced, but isolation of agranular cortex was in keeping with experimental findings (Fulton, 1951).

Autonomic responses similar to those accompanying emotion could be obtained from stimulation of a continuous zone of agranular cortex extending from the anterior cingulate gyrus to the posterior orbital gyri and temporal regions (Smith, 1945; Livingston et al., 1948). Experimental ablation of these areas produced changes in reaction to environment with loss of fear, diminished aggression, quiesence, and increased tameness (Ward, 1948).

Glees et al. (1950) had shown that fibres from the anterior cingulate cortex of Area 24 could be traced into the posterior orbital areas and since their stimulation gave rise to autonomic responses they must possess further hypothalamic connections which could be divided in the sub-caudate region. Le Gros Clark \& Meyer (1950) had demonstrated projections from Area 13 to the ventro-medial hypothalamic nuclei which traverse the subcaudate region.

Certain neuro-anatomists in personal discussion suggested that the incision might involve the substantia innominata. At first we assumed that this was so and that in this case fibres from the amygdala to hypothalamus and return pathways from hypothalamus to the amygdala (Powell, Cowan \& Raisman, 1963) would be severed within the target area. A projection from the amygdaloid nucleus and pyriform lobe (Nauta, 1961) passes through the substantia to the hypothalamus and dorso-medial nucleus of the thalamus, whence it is distributed from the parsmagnocellularis to the caudal portion of the orbito-frontal cortex. It was not possible to check the site of the lesion produced by stereotactic operation until elderly patients died from natural 
causes as there was no operative mortality. When eventually this material became available it could be seen that stereotactic lesions over Areas 13 and 14 did not extend quite so far as the substantia innominata of Reichart which lay immediately behind it (Corsellis \& Jack, 1973; Newcombe, 1973), and therefore the amygdalo hypothalamic fibres were not directly severed. However, fibres from the amygdala pass to the parsmagnocellularis of the dorso-medial nucleus and are then distributed to the caudal orbito-frontal cortex (Nauta, 1962); intracortical degeneration being dense in the caudal orbital frontal gyrus, which is occupied chiefly by Area 13, and thus the terminal radiation from the amygdala would be interrupted at this point, hence a localized lesion in the subcaudate region would exert an influence on the emotional activity subserved by these agranular areas.

Over the years it has been shown that the subcaudate region forms a good target for stereotactic surgery, for not only are there agranular cortical connections already described but recent studies indicate that connections from the frontal cortex to the hypothalamus, which bring the external milieu into association with the limbic system, also pass through this zone.

Regions of convergence within the brain have been demonstrated (Jones \& Powell, 1970) for fibres derived from visual auditory and sensory areas which pass by step-by-step progression to sites of convergence in the tips of the temporal lobes and in the frontal cortex. Fibres from the convexity of the frontal lobe then converge again on to the orbital aspect of the lobe, from which fibres pass down beneath the head of the caudate nucleus over Area 13 to converge upon the substantia innominata and hypothalamus (Nauta, 1962, 1964). A lesion at this site will therefore affect not only the connections of a proportion of the limbic system but will also interrupt fibres which are presumably concerned in bringing the external milieu, represented by the visual auditory and proprioceptive areas of the brain, into association with the hypothalamus after monitoring by the frontal cortex (Nauta, 1971). The region

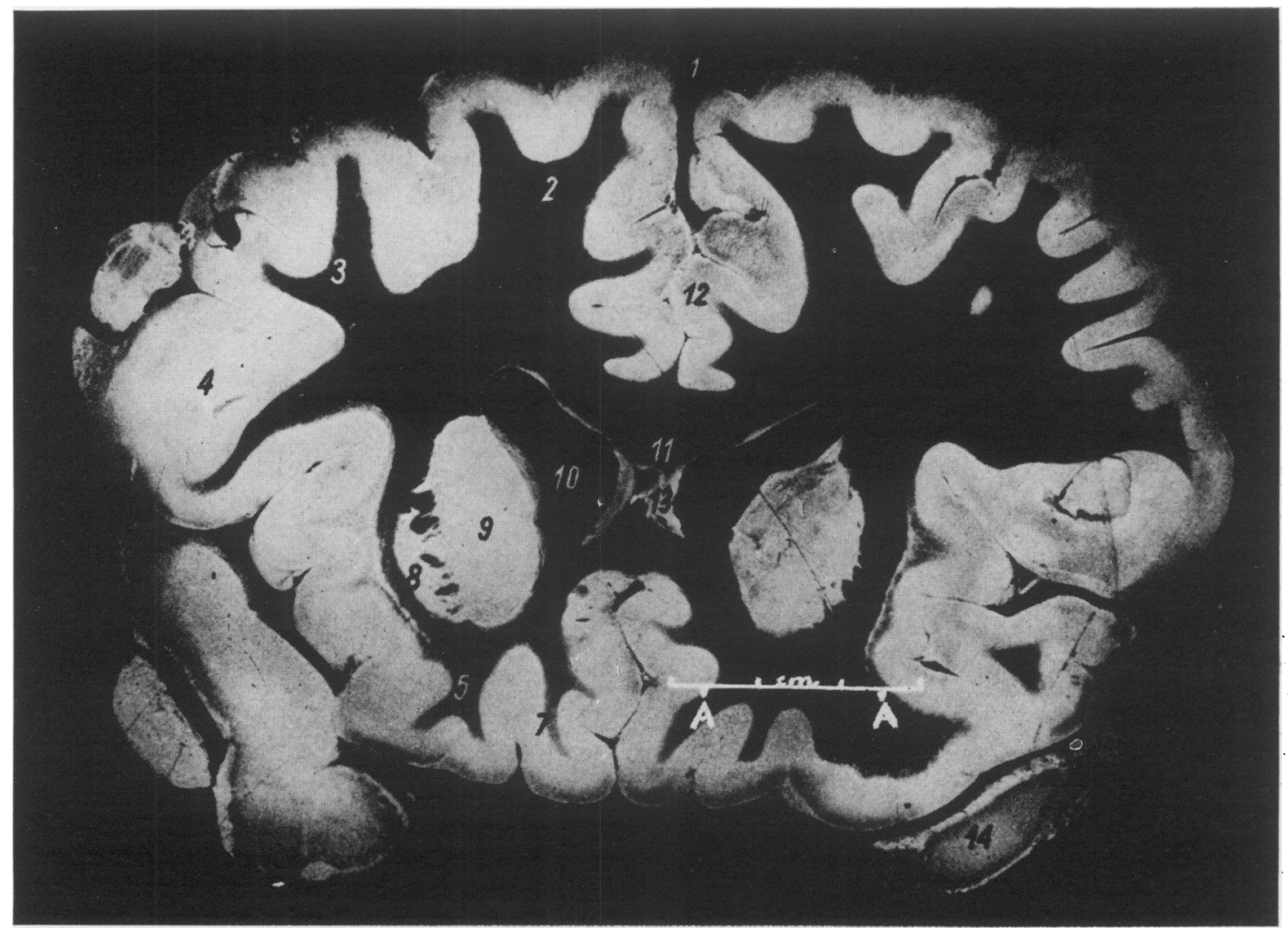

Fig. 2. Anteroposterior view of the original target site $(A-A)$ which has now been reduced somewhat in transverse extent overlying Area 13 and part of 14 of orbital cortex. Fibres descending to the hypothalamus pass downwards from its inner border beneath the caudate nucleus (9). 
beneath the head of the caudate nucleus and overlying Area 13 acts as a funnel through which these fibres must pass (Fig. 3).

It is perhaps over ambitious to attempt to explain the modus operandi of this operation on a purely anatomical basis. Does the operation produce its effect by modifying the intensity of emotional reactivity through limbic connections, or does it produce a more specific effect upon the cause of abnormal reactivity, as Bridges (1972) has suggested?

In phobic anxiety states, in patients exhibiting extreme agitation and distress, with panic reactions, severe anxiety neurosis and hyperchondriasis, an interruption of limbic connections might well contribute to the benefit observed, and also in cases of self mutilation, but as Bridges (1972) has postulated, it is probable that other connections are involved in the nearly specific effect produced by this operation in cases of resistant depression. There is considerable supporting evidence that endogenous depression is associated with depleted monoamine levels in the hypothalamus (Smythies, 1970). It may well be that the effect of operation on fronto-hypothalamic connections exerts an influence either on a reduced production of monoamines in the hypothalamus, or by interruption of the continuous feed-back which increases the seriousness of this deficiency.

Subcortical projections from the frontal cortex extend to the hypothalamus and the tegmentum in the mid-brain. Return pathways, presumably bringing the internal milieu into relation with consciousness ascend through the hippocampal fornix circuit to the medial nucleus of thalamus and thence to the cingulate and frontal cortex, and also through the medial longitudinal bundle and diagonal band of Broca to the temporal lobe. Additional descending connections between the frontal cortex and limbic system consist of the projection from the inner portion of the frontal lobe through the cingulum fibre bundle which curves round the splenium to the presubiculum and hippocampus. A pathway, recently described by Van Hoesen et al. (1972), consists of afferent fibres from Areas 12 and 13 to the entorhinal cortex of the temporal lobe, with further projections to the hippocampus.

\section{Follow-up studies}

Depression is favourably influenced in some $70 \%$ of cases. In 150 cases reviewed by Ström-Olsen \& Carlisle (1971), psychiatric rating was assessed in five groups:

Grade 1. Completely recovered.

Grade 2. Improved-no treatment required, with slight residual symptoms.

Patients in Grades 1 and 2 are therefore free of medical care.
Grade 3. Improved, but still needing treatment with persistent symptoms.

Grade 4. Unchanged.

Grade 5. Worse.

TABLE 1. Psychiatric ratings and diagnoses

\begin{tabular}{lrrrrrrrr}
\hline \multirow{2}{*}{ Diagnosis } & \multicolumn{4}{c}{ Rating } & & \multirow{2}{*}{ Total } \\
\cline { 2 - 5 } & I & II & III & IV & V & \\
\hline Recurrent depression & 20 & 5 & 12 & 8 & - & 45 \\
Involutional depression & 3 & 2 & 1 & - & - & 6 \\
Depression (other types) & 8 & 4 & 5 & 7 & - & 24 \\
Anxiety state & 10 & 9 & 11 & 16 & - & 46 \\
Obsessional neurosis & 7 & 3 & 3 & 6 & 1 & 20 \\
Schizophrenia & - & - & 2 & 3 & - & 5 \\
Others & 1 & 1 & 1 & 1 & - & 4 \\
Total & 49 & 24 & 35 & 41 & 1 & 150 \\
\hline
\end{tabular}

There were forty-five cases of recurrent depression; twenty had made a complete recovery, five were in grade 2 but required no further treatment, that is there were $55 \%$ of cases free of medical care, a further twelve cases, or $26.6 \%$, had improved but still needed treatment, and only eight were unchanged. Diagrams of the duration of illness and the number and duration of attacks, and the intervals of normality between the attacks before and after operation show that in those patients who reach psychiatric rating grade 1 , there is a complete cessation of attacks after operation in almost every case, and in those who reach grade 2 , free of medical care, or grade 3, still requiring treatment, although there were some attacks, these attacks were never of the intensity that they had been prior to operation. There were very few cases of involutional depression but five out of six became free of medical care. In other types of depression which included those in which the condition was chronic, sometimes associated with mild paranoid ideas and severe hyperchondriasis, $50 \%$ became free of medical care.

In anxiety states the outcome was somewhat less favourable. Nineteen out of forty-six $(42 \%)$ became free of medical care and eleven cases, representing $25 \%$, were improved.

In twenty cases of obsessional neurosis $50 \%$ became free of medical care and a further $15 \%$ were improved. Patients who were in grades 2 and 3 showed marked lessening of tension and all were free of depression, although their compulsions were still present to a diminished extent. Two of the patients in grade 4 had had previous unsuccessful surgical treatment by leucotomy or rostral leucotomy. The only case in the whole series who appeared to be worse after operation was a female whose illness was of 30 years' duration, who after operation developed in addition to her hand-washing mania, 
compulsions to wash her arms, face, and feet excessively. This patient should really be regarded as incurable, for 11 months later bilateral cingulectomy was performed with only marginal improvement.

In a recent comparative review of patients with obsessional neurosis and depression (Bridges, Goktepe \& Maratos, 1973), overall improvement was also assessed on a 5 point scale, but the definitions were slightly different, emphasizing social function rather than need for treatment. In StrömOlsen \& Carlisle's review (1971) category 2, much improved, implied that no treatment was required, but Bridges et al. (1973) point out that some patients remain on relatively small doses of drugs such as diazepam and imipramine for long periods after operation when there is little clinical indication for their use, and they have therefore modified their scale so that category 2 indicates the presence of mild symptoms with little or no interference with daily life, even although some medication may still be taken. Categories 1 and 2 imply definite improvement since operation. Category 3 indicates that there has been some improvement, but response of this degree cannot always be confidently attributed to the operation, and so it seemed better to group these cases with those in category 4 in which there had been no change. Therefore the results were considered in terms of a patient whose outcome was good (categories 1 and 2) compared with those whose response was poor (categories 3 and 4); no patient in this series reporting that they were in any way worse. Twenty-four patients with primarily obsessional complaints were compared with twenty-four matched patients with primary complaints of depression, each matched for age, sex, and examined at least 3 years after operation. The duration of illness for all patients was about 10 years. Taking all categories of improvement together $(1,2$, and 3$)$, only two from each of the obsessional and depressed groups of patients remained not improved, and none was made worse, but if more definite degrees of improvement only were taken, i.e. categories 1 and 2 , then $67 \%$ of the obsessional group did well, compared with $71 \%$ of the depressives. Bridges' et al. (1973) conclusion is that it is clear that cases presenting with obsessional symptoms do not do worse as a group than patients with primary depression.

Ström-Olsen \& Carlisle's review (1971) has shown that the duration of illness has little effect upon the outcome, particularly in depression, and many patients whose illnesses were up to 20 years' duration, and two patients whose illness was over 20 years' duration, reached psychiatric rating grade 1 . In obsessional neurosis also the duration of illness appeared to have little effect upon the final result, but in anxiety states those whose illness had been from 2 to 5 years' duration did somewhat better than those whose illness was more prolonged. Ratings for capacity for work and pleasure indicated a very good social recovery. In the work ratings, before operation only one patient had a full work rating, seventy-two had a partial rating, twenty-eight were self occupied and thirty-five did nothing at all, whereas after operation seventy-two were fully occupied, thirty-one partially, eighteen self occupied and only fifteen did nothing at all. In the pleasure rating-no patient had a full pleasure rating prior to operation-forty-three had a partial rating and ninety-three had none, whereas after operation seventy-four had full pleasure rating, thirty-two partial, and only thirty had none.

There was an almost complete absence of symptoms of personality damage, such as are met with in the post-leucotomy syndrome of former years. Of 150 patients, $129(86 \%)$ showed no undesirable symptoms at all. Twenty-one developed some postoperative behavioural and psychological changes which were minor and trivial in seventeen $(11.4 \%)$ and lasting and troublesome in four $(2 \cdot 6 \%)$, none of which were disabling. With the exception of two cases, who complained of difficulty in concentrating and remembering, no evidence of intellectual deterioration was detected. Twenty-three patients who at some time after operation obtained the rating of grade 1 or 2 relapsed and came under treatment again, but twelve of these regained their original psychiatric grading. Permanent relapses appeared to be significantly higher in anxiety states than in other conditions. The epileptic risks appear to be low, in this series less than $1 \%$. This is therefore a safe operation which can be used with confidence as a nextstage in treatment when an impasse is reached in potentially curable cases.

\section{Clinical observations}

Schizophrenia presents very few indications for surgical intervention of any type. Fewer than onefifth of the patients subjected to the old leucotomy operation made a satisfactory recovery, the remaining four-fifths being confined to mental hospital exhibiting evidence of intellectual or physical damage and constituting a permanent reminder of the failure of psychosurgical treatment. In my series of restricted orbital undercutting operation there were sixty-six cases of schizophrenia in the first 450 operations (Knight, 1964), of whom only sixteen became free of medical care, and in the whole 680 cases of stereotactic tractotomies we have operated upon only six cases. With careful selection it is possible in patients with well preserved personalities to produce a reduction in aggressive behaviour which is of benefit in relation to nursing care. Impulses of self destruction may likewise be favourably influenced and also depression, but owing to the success of 
modern drug treatment the indications are very few.

J.G., aged 23, married with one child, had sustained a chronic schizophrenic illness since the age of 19 with five previous mental hospital admissions. She was a rather dull person who did not achieve much in school or in subsequent occupations prior to her breakdown. She was readmitted in 1968 after a relapse of a chronic schizophrenic illness and was confined under close supervision, she was not hallucinated, but lacked drive and energy, her mood was variable and incongruous, there was evidence of disturbed thinking and she was pre-occupied with the thought that a brain operation would make her more intelligent. She attempted suicide on several occasions by self strangulation using bizarre contrivances to effect this end. She responded only shortly to medication or ECT. In view of the suicidal attempts operation was performed in November 1969. In April 1970 she left mental hospital for rehabilitation with a job in a protected environment. She left the rehabilitation unit in October 1971, obtaining a post in a local factory as a finisher earning $£ 19$ a week, had formed a new emotional attachment, her previous marriage having broken down, and in December 1972 reported that she was keeping well and very happy in her employment.

Syndromes of depression constitute the main indication for operation. Immediate or gradual recovery may be observed and continue with increasing benefit for up to 2 years, temporary relapses settle well with appropriate treatment and during rehabilitation patients may respond to drug therapy or ECT which had been ineffectual before. Slow recovery is more common in patients with anxiety or with hysterical and hyperchondriacal symptoms superimposed on a depressive illness or in those with inferiority feelings, and it is important to observe that when these features are superimposed upon depression they do not constitute a contra-indication to operation.

An example of slow recovery is that of a patient aged 53 who had suffered with chronic recurrent depression with manic episodes for 25 years, the pattern was that of a period of 6-9 months each year in which he was severely depressed and for the remainder of the time there were episodes of euphoria, with hypomanic behaviour, with poor response to drugs and ECT. His disability eventually led to his closing down his business. He was operated on in 1970. Fourteen months after operation his wife wrote that for the first 6 months he still suffered from bouts of depression, he still felt inadequate, inferior to other men, incapable of making a living and he still felt the need to stay in bed so as not to face people. After the first 6 months his state improved almost daily. He started to work full time 11 months after operation and there are now no more bouts of depression and no 'highs' either. He is logical, sees things in their right perspective, is not running away from difficulties any more and is even tempered and happy; in other words 'I have now a husband whom I previously suspected I had under all the phobias and tensions which he suffered from.'

Operation may be performed in patients of advanced years and poor physical condition suffering from hypertension, cardiac decompensation and pulmonary disease Numerous successes have been obtained in geriatric patients in the oldest age groups from 70 to 86 years (Knight, 1966).

A woman of 79 with 14 years of mental hospital admission suffered from melancholia with several suicidal attempts. She was in the last stages of dissolution, mouthing, muttering, and restless, she had chewed her lips into a mass of granulations, she was covered with bed sores, crippled with arthritis and had crepitations at both bases, and she would shortly have died. Operation was performed in two stages. Three months after operation she was no longer bedridden but was up and about exhibiting a vivid play of emotional expression and left mental hospital for the first time in 14 years. She spent 18 months at home living a perfectly normal existence until she eventually died from natural causes.

A further old lady aged 75 had a 40-year history of recurrent depression. Prior to operation she was almost mute, in depressive stupor, occasionally casting her eyes upwards to beg her Maker to take her, and when questioned as to how things looked she? stated that 'everything is black-all dead'. Three months after operation she was living a perfectly normal life as a village grandmother, enjoying reading and looking after the children and engaging in full normal activity appropriate to her age.

Success can also be obtained in elderly patients in mixed syndromes combining anxiety, depression, and hyperchondriasis, as illustrated by the case of a Polish gentleman aged 70, with a 15-year history of increasing tension, depression, and somatization. Over the years he became more and more preoccupied with his health, unable to cope, and most of the time agitated. He did not get out of bed for 4 years, he was repeatedly calling his relatives and the priest, giving his money away believing that he was on the verge of death. Following operation he is quiet and composed, although he does complain from time to time of rheumatic pains. He describes the effect of operation as being 'a miracle to my health and giving me easiness of mind'.

Chronic and recurrent depression respond well at all ages. A melancholic male aged 46, with five mental hospital admissions in 4 years, full of selfreproach, guilt and unworthiness, was actively suicidal and attempted to starve himself. In a state of complete psychomotor retardation he would not 
speak, eat or drink, and lay in bed with his head covered with the bed clothes. Following operation in 1963, within 4 months he was taking an adequate interest and was optimistic about his future. $\mathrm{He}$ has since returned to regular employment in the gear box assembly section of a large car factory.

A housewife, aged 37, following the death of her father, had for 10 years exhibited depression involving ten suicidal attempts, of which seven occurred in the last 5 years, the last had resulted in a temporary paralysis of her left arm from cerebral anoxia. She stated quite definitely that she intended to kill herself, and that she would do so because she was convinced that she could obtain no help from existing methods of treatment. Following operation she made a satisfactory recovery and became once again a happy married woman. A particularly gratifying feature was her emotional reaction to her young son who had been growing up during the 10 years of illness. During that time she has had no feeling towards him, but after operation she developed a normal maternal love. Two years after operation she discovered that she had developed cancer of the breast. She held an objective discussion with the surgeon as to whether she should have an amputation or deep X-ray therapy, choosing deep X-ray therapy in order to avoid mutilation as she had already been sterilized as part of her psychiatric treatment. She has satisfactorily withstood the impact of this serious stress, exhibiting no more than the normal anxiety of any woman, and has obtained an excellent clinical result in so far as this second illness is concerned.

Juvenile and adolescent depression sometimes associated with anorexia or self mutilation has also responded favourably. One seriously disturbed girl aged 23, who was addicted to head bashing and self mutilation since the age of 10 , had failed to respond to an operation of cortical undercutting but improved remarkably following a stereotactic operation. How this additional effect was produced must be a matter of speculation. Vaernet \& Madsen (1970) described thirteen cases of severely disturbed schizophrenia in which operation upon the amygdala produced a good effect in ten, but in three in whom frequent self mutilation persisted this was relieved by an additional operation in the subcaudate region. It seems improbable that the additional effect was produced by interruption of amygdalo-cortical fibres but more than probable that the result could be related to the early experimental observations of Wheatley (1944), who showed that projections to the ventro-medial hypothalamic nuclei exerted influence on pathways which were executively concerned in the expression of rage.

Many patients who have undergone prolonged psychiatric treatment are taking a very high dosage of drugs and become in a sense addicted to the drugs they are receiving. An immediate reduction in drug requirement is observed in all cases following operation, and hence we have employed the operation to relieve addiction in patients taking barbiturates or alcohol in an attempt to escape from a tension situation, and have succeeded in breaking the addiction where the addiction has been the product of depression (Knight, 1972b). We have had no success whatsoever in the treatment of chronic alcoholism and have only obtained relief in two out of seven cases of heroin addiction in young subjects who had taken the drug to gain acceptance within a group and have been unable to escape from it.

The study as a whole indicates that the best results are obtained in syndromes associated with depression and those which have had their onset on pregnancy. But whilst results may be expressed in relation to the major diagnostic categories of depression, anxiety states, and obsessional illness, one has come to realize that the employment of a strictly localized operation, time and time again at precisely the same point, reveals differences in response in subcategories which exist within the major diagnostic groups of patients exhibiting comparable symptoms.

In anxiety states the influence of depression in relation to a satisfactory result is so marked that $I$ am tempted to speculate whether some of these cases should really be regarded as a variant of a depression syndrome. Modern thinking inclines to the view that anxiety is frequently an overt expression of an underlying depressive illness, and many patients, classified as anxiety states in whom a depressive element can be detected appear to carry a more favourable prognosis.

There are of course examples of patients with phobic anxiety and extreme agitation and distress in whom an operation can produce a remarkable result. L.G.R., aged 59, was a lifelong worrier and obsessional perfectionst but a man of drive, he had always been selfish and self-concerned; his wife, who was sensible, had put up with great fortitude with much invalidism. He later suffered from hypertension and an enlarged heart, became more and more tense, scared, and in a state of panic, always over anxious and highly strung. He developed hypertensive heart failure and became so acutely distressed that it was felt that operation was urgently required to relieve the agitated mental state. On admission he was agitated, groaning, gasping and sweating, unable to sleep and felt that he was dying. He was in hypertensive heart failure and the outlook was very poor. With digitalization his physical condition improved. Operation was performed on the 19 March 1962. On 16 April 1962 the notes state: 'The change is quite remarkable. He was cheerful, 
active, and free of anxiety symptoms, in fact the difficulty now was to control his over activity which tended to throw undue strain on his limited cardiac reserve.' He later developed a cerebro-vascular accident with aphasia, but this improved, and he was discharged, although physically ill he was unconcerned, without gross anxiety or excessive tension.

Those patients with anxiety symptoms who fail to show a response or relapse permanently after operation are usually those with long-standing illness and personality defects which can be detected in childhood or early adult life.

In obsessional illness also, there appeared to be a contrast between the better results obtained when the obsessional illness is associated with depression, as compared with the relatively small number of cases of pure obsessional neurosis of early age onset which always carry a bad prognosis. In the former category, a woman of 38 had suffered from tension and anxiety since childhood; at 19 following marriage to a sadist she developed multiple jerks and sweating so severe that she had to change her clothes several times a day and obsessional tidiness and depression also developed. Following operation 10 years ago she was immediately dramatically improved; within 2 months the jerking, sweating and suicidal impulses were gone, she was able to put things away in the wardrobe and forget all about abnormal tidiness, 'formerly it had taken me ages to get away from it-I seemed to be glued to it'. She has maintained this complete improvement.

No absolute reliance can be placed upon the age of onset of obsessional syndromes in relation to prognosis. Bridges et al. (1973) have shown that those patients with obsessional symptoms who do poorly after operation have illnesses with an onset which tends to be earlier than those patients who do well. Age of onset appears to be a useful guide to prognosis but must be considered in association with other features, such as depression or onset of symptomatology during pregnancy. There does seem, however, to be a relatively small group of cases characterized by pure obsessional symptoms, without depression, of early age onset which has a bad prognosis. This may form a rare but separate illness corresponding in prognosis to Pollitt's (1957) observation that true obsessional states are among the few illnesses which still can torture patients for a life time.

I have recently reviewed a woman of 33 who at 18 developed obsessions of contamination. Cortical undercutting in 1957 followed by cingulectomy in 1964 produced no improvement. In 1972 her hands were still almost raw from continuous washing.

Finally we come to the question as to whether further stereotactic procedures can be employed with benefit in those patients in whom an operation in the subcaudate region has failed to produce sufficient improvement. Operations upon the phylogenetically older areas of the brain in the amygdala, the hippocampus and cingulum are often concerned with the control of violent behaviour, but in view of the claims which have been advanced from America and elsewhere concerning the value of operation on the cingulum bundle we decided to explore the possibilities of a further lesion in that area (Knight, 1973).

The cingulum contains further relays passing from the mesial portion of the frontal lobe to the hippocampus and hypothalamus which can form a further projection bringing frontal cortical areas into association with the limbic system, and it also receives direct reinforcements from the fibres derived from sensory cortical areas on their way to convergence at the frontal pole. It forms a definite bundle lying $1.3 \mathrm{~cm}$ from the middle line. We have felt that a simple division of the cingulum bundle does not

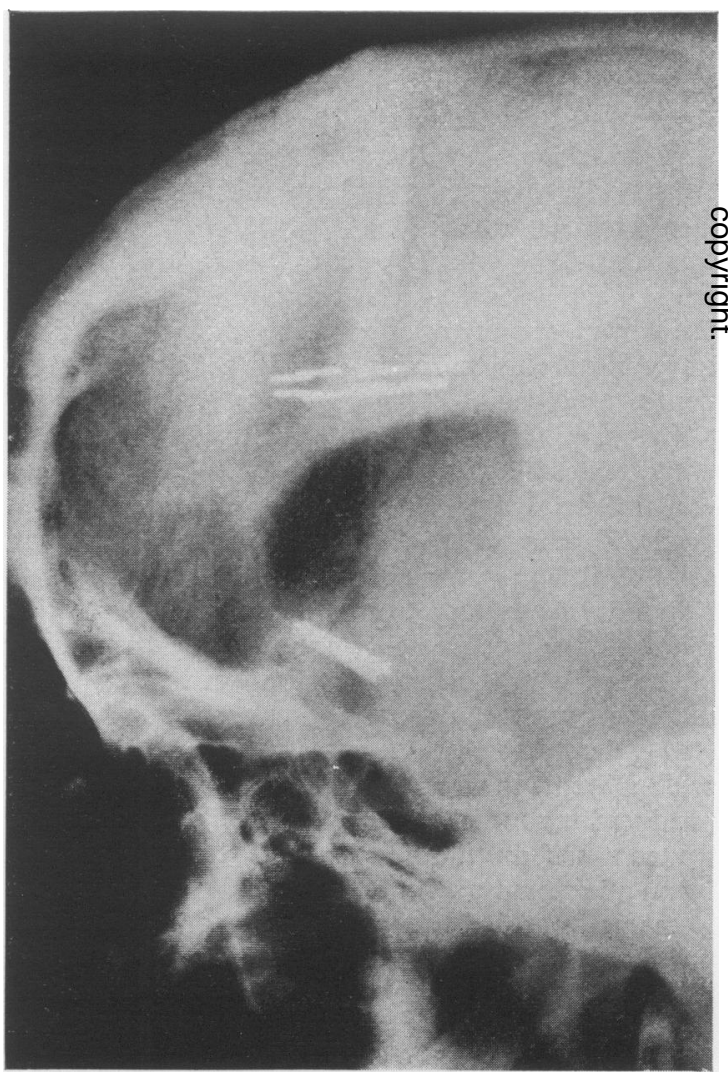

Fig. 3. X-rays showing radioactive seeds inserted into the subcaudate region and also into the cingulum bundle in a position to block fibres passing from the antero medial nucleus to the cingulate cortex through the internal capsule in a patient requiring two operations. 
satisfactorily reproduce the effects obtained by the old operation of cingulectomy, which produced excellent results in obsessional illness, for in this operation the cingulate cortex is sucked out to a depth which would involve the cingulum bundle, part of the cingulate cortex of Area 24 is removed and the incision is carried back far enough to interrupt fibres coming from the anterior-medial nucleus of the thalamus to the cingulate cortex. We have therefore produced a linear lesion $1.5 \mathrm{~cm}$ in length which will interrupt afferent relays to the cingulate cortex as well as the cingulum bundle, and we have found that further improvement could be obtained in a patient in whom severe obsessional rumination over guilt feelings had persisted, despite the relief of depression by the subcaudate operation. We have also obtained improvement in two patients suffering from severe anxiety as part of a mixed syndrome in whom phobic anxiety alone has persisted. One patient whose symptoms were of 10 years' duration has now returned to her nursing career. The double lesion can therefore help at times in mixed syndromes in improving obsessional and phobic features, but we have found no benefit whatsoever from a lesion in this area in patients with primary obsessional illness of early age onset, whose failure to respond is presumably due to the nature of their disease rather than defects of operation at any site. In only one case was marginal improvement obtained. Operation was entirely without effect for some years in a young Irish doctor with fears of contamination who had been an obsessional hand washer since the age of 18 . Two years after operation he was reported making a slight improvement, but whether this could be attributed to the operation which he had undergone was extremely doubtful.

In conclusion, I would suggest that since the full effect of operation may not be apparent until 1 or 2 years have passed, sufficient time should always be allowed to elapse before further surgical procedures are undertaken in patients who are slow to improve. It is only in this way that an accurate assessment of the true effect of local operations can be obtained. Also, it is important to define the extent as well as the location of a lesion. The subcaudate lesion which has length and breadth and which isolates a cortical area and destroys a zone of white matter within a rectangle, cannot be accurately reproduced by the formation of a small globular lesion within that area.

\section{References}

Bridges, P. (1972) Personal communication.

Bridges, P., GoKtePe, E.O. \& Maratos, J. (1973) A comparative review of patients with obsessional neurosis and with depression treated by psychosurgery. British Journal of Psychiatry, 123, 663.

Corsellis, J.A.N. (1969) Personal communication.
Corsellis, J.A.N. \& JACK, A.B. (1973) Neuropathological observations on yttrium implants and on undercutting in the orbito-frontal areas of the brain. Proceedings of the Third International Congress on Psychosurgery, Cambridge, England, 1972. In: Surgical Approaches in Psychiatry. Medical and Technical Publishing Co., Lancs.

Fulton, J.E. (1951) Frontal Lobotomy and Affective Behaviour. Morton, New York.

Glees, P., Cole, J., Whitty, C.W.M. \& Cairns, H. (1950) The effects of lesions in the cingular gyrus and adjacent areas in monkeys. Journal of Neurology, Neurosurgery and Psychiatry, 13, 178.

Jones, E.G. \& Powell, T.P.S. (1970) An anatomical study of converging sensory pathways within the cerebral cortex in the monkey. Brain, 93, 793.

KNIGHT, G.C. (1960) 300 cases of restricted orbital cortex undercutting. Proceedings of the Royal Society of Medicine, 53, 728 .

KNIGHT, G.C. (1964) The orbital cortex as an objective iu the surgical treatment of mental illness -450 cases of open operation and the results of development of the stereotactic approach. British Journal of Surgery, 51, 114.

KNIGHT, G.C. (1965) Stereotactic tractotomy in the surgical treatment of mental illness. Journal of Neurology, Neurosurgery and Psychiatry, 28, 304.

KNIGHT, G.C. (1966) Intractable psychoneurosis in the elderly and infirm. British Journal of Geriatric Practice, 3, 7.

KNight, G.C. (1972a) Psychosurgery to-day. Neurosurgical aspects. Proceedings of the Royal Society of Medicine, 65, 1099.

KNIGHT, G.C. (1972b) Bilateral stereotactic tractotomy-an experience of 450 cases. In: Psychosurgery, p. 267. Charles C. Thomas, Illinois.

KNIGHr, G.C. (1973) Additional lesions in the cingulum following failed operations in the subcaudate region. Proceedings of the Third International Congress on Psychosurgery, Cambridge, England, 1972. In: Surgical Approaches in Psychiatry. Medical and Technical Publishing Co., Lancs.

KNight, G.C. \& Tredgold, R. (1955) Orbital leucotomya review of fifty-two cases. Lancet, $\mathrm{i}, 981$.

Le Gros Clark, W.E. \& Meyer, M. (1950) Anatomical relationships between the cerebral cortex and the hypothalamus. British Medical Bulletin, 6, 341.

Livingston, R.B., Fulton, J.F., Delgado, J.M.R., SaChs, E., BRENDleR, S.J. \& DAVIS, G.D. (1948) Research Publications. Association of Nervous and Mental disorders, 27, 405.

NAUTA, W.J.A. (1961) Fibre degeneration following lesions of the amygdaloid complex in the monkey. Journal of Anatomy, 95, 515.

NAUTA, W.J.A. (1962) Neural associations of the amygdaloid complex in the monkey. Brain, 85, 505.

NAUTA, W.J.A. (1964) Some efferent connections of the prefrontal cortex in the monkey. In: The Frontal Granular Cortex and Behaviour (Ed. by J. M. Warren and K. Akert), p. 397. McGraw-Hill, New York.

NAUTA, W.J.A. (1971) The problem of the frontal lobe and reinterpretation. Journal of Psychiatric Research, 8, 167.

Newcombe, R. (1973) Anatomical placement of lesions in the ventro-medial segment of the frontal lobe. In: Surgical Approaches in Psychiatry, p. 83. Medical and Technical Publishing Co., Lancs.

PollitT, J. (1957) Clinical history of obsessional states. British Medical Journal, 1, 194.

Powell, T.P.S., Cowan, W.M. \& Raisman, G. (1963) Olfactory relationships of the diencephalon. Nature, 199, 710. 
Psychosurgery (1972) Proceedings of the Second International Conference on Psychosurgery, Copenhagen, 1970. Charles C. Thomas, Illinois.

SMITH, W.K. (1945) The functional significance of the rostral cingular cortex as revealed by its responses to electrical excitation. Journal of Neurophysiology, 8, 241.

Smythies, J.R. (1970) Brain Mechanisms and Behaviour. Blackwell Scientific Publications, Oxford.

Ström-Olsen, R. \& Carlisle, S. (1971) Bi-frontal stereotactic tractotomy. A follow-up study of its effects in 210 patients. British Journal of Psychiatry, 118, 141.

VAERNET, K. \& MADSEN, A. (1970) Stereotactic amygdalo- tomy and basofrontal tractotomy in psychotics with aggressive behaviour. Journal of Neurology, Neurosurgery and Psychiatry, 33, 858.

Van Hoesen, G.W., Pandya, D.N. \& Butters, N. (1972) Cortical afferents to the entorhinal cortex of the rhesus monkey. Science, 175, 1471.

WARD, A.A. (1948) The anterior cingular gyrus and personality. Research Publications. Association of Nervous and Mental Disorders, 27, 438.

WheAtley, M.D. (1944) The hypothalamus and affective behaviour in cats. Archives of Neurology and Psychiatry, 52, 296. 